\title{
The Fear of Cancer from the Standpoint of Oneself, the Opposite Sex and the Fear of Side Effects of Cancer Treatment
}

\author{
Keeho Park, MD, PhD ${ }^{1,2}$ \\ Youngae Kim, $\mathrm{PhD}^{1}$ \\ Hyung Kook Yang, MD, MPH ${ }^{1}$ \\ Hye Sook Min, MD, PhD'
}

\begin{abstract}
Purpose
It is important to understand the differences between men and women when it comes to attitudes and risk perception toward disease. This study aimed to explore the fear of cancer from the standpoint of themselves and the opposite sex by cancer type.
\end{abstract}

\section{Materials and Methods}

A cross-sectional survey with a representative sample was conducted.

\section{Results}

The least and the most feared cancers in men were thyroid cancer and lung cancer, respectively. When men assumed the perspective of women, the least and the most feared cancer were thyroid cancer and stomach cancer, respectively. The least and the most feared cancers in women were thyroid cancer and stomach cancer, respectively. When women assumed the perspective of men, the least and the most feared cancer were prostate cancer and lung cancer, respectively. When both men and women assume the perspective of the opposite sex, the fear of sex-specific cancer was relatively low compared to the actual responses of both men and women. The top six of the most feared side effects of cancer treatment were pain, psychological problems, general weakness, digestive dysfunction, fatigue, and appearance change. These were the same between men and women.

\section{Conclusion}

Health care providers and caregivers in the family should provide care with more attention to the differences in thoughts about cancer between men and women. Health care providers should provide care with more attention to the differences in these problems between men and women.

\section{Key words}

Cancer, Fear, Complication, Sex, Difference

\section{Introduction}

Fear is the body's natural, survival-oriented response for protecting itself from danger or threats [1]. However, fear for health has both positive and negative aspects [2]. Fear may serve as a motivation for preventive action $[3,4]$ or a hindrance to disease control [5]. In a broad sense, risk perception of people involved with the disease is important not only for the prevention of the disease, but also for their management [6].

Cancer is one of the most feared diseases [7]. Cancer is more frightening because the treatment process is painful and its aftereffects significantly reduce the quality of life $[8,9]$. The physical, mental, social, and economic problems caused by cancer have a significant impact on not only the patient but also on the caregiver's family [10]. Cancer is not a single disease and different types of cancer can be considered as different diseases [11]. Thus, fear of cancer and other psychological reactions to cancer may be different according to various cancer types.

The problem is that the diversity of these cancers is complicated more by the sex factor. Sex factor does not simply mean two biologically distinct groups, because the various aspects of suffering through a disease can be different between men and women $[10,12,13]$. Effects of sex factor can be seen in the research findings that show that there is a difference between the care, attitude, or behavior towards cancer patients in male and female spouses $[14,15]$. In addition, the problems that arise due to insufficient consideration of the difference in risk perception between men and women in performing health 
communication have increased [16,17].

A person's health behavior can be affected by both their own as well as their family members' risk perception [18-20]. In cancer patients, risk perception of the patient and his or her family may affect the care of the patient [20,21]. In addition, there are reports of better outcomes when considering not only individual patients but also families in patient care [22]. In this context, it is important to understand the differences between men and women's attitudes and risk perception towards diseases. Although studies comparing risk perceptions of cancer fears between men and women exist [23,24], few studies have examined how they think from the perspective of the opposite sex. Moreover, knowledge of how men and women are guessing the thoughts of the opposite sex may allow us to understand how men and women understand differences between sexes. In this study, we explored the fear of cancer from the standpoint of themselves and the opposite sex by cancer type, and those fears were compared between men and women. We also investigated the fear of side effects of cancer treatment and compared it between men and women.

\section{Materials and Methods}

\section{Study population}

A cross-sectional survey was conducted in May 2017. The survey used a proportional quota random sampling design to select a representative sample of non-institutionalized Koreans who had no experience of cancer for themselves or their family members. With stratification by age and sex in each 17-administrative district based on the 2016 census of Korea, a probability proportional to size method was used to sample. Of the randomly selected 1,460 responders who were consecutively telephoned, 460 responders were excluded because of absence and refusal to participate for several reasons, or because the responder was a cancer patient or had a family member with cancer. A total of 1,000 participants were finally chosen and a face-to-face interview was conducted by professional interviewers of research firm Metrix Corporation (Seoul, Korea). The interview process was carefully reviewed and monitored by the researchers.

\section{Assessment}

Sociodemographic variables such as age, marital status, education level, income level, and economic activity were included. The variables were categorized as follows: age (20-29, 30-39, 40-49, 50-59, 60-69, and 70 years and older), marital status (married, widowed, divorced/separated, or single), education level (middle school or lower, high school, and college graduate or higher), average monthly individual income $(\leq 0.99,1-1.99,2-2.99,3-3.99,4-4.99, \geq 5.0$ million $\mathrm{KRW} / \mathrm{mo}$ ), and economic activity (employed, housewife, student, or not employed).

The following questions were asked about the least feared cancer and the most feared cancer; "If you had cancer, which of the following would you fear less? Please check the 1st, 2nd and 3rd ranks of the less feared cancers. And in the case of men, assume that you're a female, and in the case of women, assume that you're a male." "If you had cancer, which of the following would you fear most? Please check the 1st, 2nd, and 3rd ranks of the most feared cancers. And in the case of men, assume that you're a female, and in the case of women, assume that you're a male." Cancers of choice were stomach cancer, colon cancer, lung cancer, liver cancer, thyroid cancer, prostate cancer, bladder cancer, renal cancer, pancreatic cancer, cancer of bile duct and gallbladder, leukemia, breast cancer, cervical cancer, uterine cancer, and ovarian cancer.

The following questions were asked about the fear of side effects of cancer treatment. "What is the most feared side effects of cancer treatment? Please check the 1st, 2nd, and 3rd ranks of the most feared side effects of cancer treatment." Side effects of cancer treatment of choice were pain, fatigue, general weakness, digestive dysfunction, sexual dysfunction, psychological problems, urological dysfunction, motor dysfunction, sensory dysfunction, appearance change, lymphedema, and infertility. The questionnaire used in this study can be found in the Supplementary Material.

\section{Statistical methods}

To compare the status of sociodemographic variables between men and women, chi-square analysis was used as a univariate analysis. For the questions about cancer fear and fear of the side effects of cancer treatment, 3 points were given for the 1st rank, 2 points for the 2nd rank, and 1 point for the 3rd rank, and the points were summed as rank scores for each type of cancer. Then each type of cancer was ranked by scores for each category such as least feared cancer or most feared cancer, and the fear of side effects of cancer treatment was ranked by the rank scores. Each type of cancer was also ranked by 5 -year relative survival rate, and the ranks were used to compare the fatalness of cancer (5-year relative survival rate) to the fear ranks mentioned above. Rank difference was calculated to show the gaps between 5-year relative survival rate and each fear rank, and between the fear rank of men or women and the fear rank generated from the opposite sex. Rank difference was also calculated to show the gaps in the fear of side effects of cancer treatment between men and women. Student's t test was used to compare the thoughts of men and women about cancer fears and the fear of side effects of cancer treatment in both men and women. The analysis was performed using SPSS ver. 16 (SPSS Inc., Chicago, IL).

\section{Ethical statement}

The present study was approved by the Korean National 
Table 1. General characteristic of the study population

\begin{tabular}{|c|c|c|c|c|}
\hline Characteristic & $\begin{array}{c}\text { Total } \\
(n=1,000)\end{array}$ & $\begin{array}{c}\text { Men } \\
(n=501,50.1 \%)\end{array}$ & $\begin{array}{c}\text { Women } \\
(\mathrm{n}=499,49.9 \%)\end{array}$ & p-value ${ }^{a)}$ \\
\hline \multicolumn{5}{|l|}{ Age (yr) } \\
\hline $20-29$ & $167(16.7)$ & $89(17.8)$ & $78(15.6)$ & 0.840 \\
\hline $30-39$ & $188(18.8)$ & $95(19.0)$ & $93(18.6)$ & \\
\hline $40-49$ & $216(21.6)$ & $110(22.0)$ & $106(21.2)$ & \\
\hline $50-59$ & $209(20.9)$ & $105(21.0)$ & $104(20.8)$ & \\
\hline $60-69$ & $206(20.6)$ & $95(19.0)$ & $111(22.2)$ & \\
\hline$\geq 70$ & $14(1.4)$ & $7(1.4)$ & $7(1.4)$ & \\
\hline \multicolumn{5}{|l|}{ Marital status } \\
\hline Married & $704(70.4)$ & $333(66.5)$ & $371(74.3)$ & $<0.001$ \\
\hline Widowed & $32(3.2)$ & $8(1.6)$ & $24(4.8)$ & \\
\hline Divorced/Separated & $34(3.4)$ & $18(3.6)$ & $16(3.2)$ & \\
\hline Single & $230(23.0)$ & $142(28.3)$ & $88(17.6)$ & \\
\hline \multicolumn{5}{|l|}{ Education } \\
\hline Middle school or lower & $88(8.8)$ & $30(6.0)$ & $58(11.6)$ & 0.002 \\
\hline High school & $422(42.2)$ & $206(41.1)$ & $216(43.3)$ & \\
\hline College or higher & $490(49.0)$ & $265(52.9)$ & $225(45.1)$ & \\
\hline \multicolumn{5}{|l|}{ Income (million KRW/mo) } \\
\hline$\leq 0.99$ & $119(11.9)$ & $36(7.2)$ & $83(16.6)$ & $<0.001$ \\
\hline $1-1.99$ & $147(14.7)$ & $36(7.2)$ & $111(22.2)$ & \\
\hline $2-2.99$ & $229(22.9)$ & $126(25.1)$ & 103 (20.6) & \\
\hline $3-3.99$ & $241(24.1)$ & $148(29.5)$ & 93 (18.6) & \\
\hline $4-4.99$ & $150(15.0)$ & $91(18.2)$ & $59(11.8)$ & \\
\hline$\geq 5$ & 114 (11.4) & $64(12.8)$ & $50(10.0)$ & \\
\hline \multicolumn{5}{|l|}{ Economic activity } \\
\hline Employed & $751(75.1)$ & $455(90.8)$ & $296(59.3)$ & $<0.001$ \\
\hline Housewife & $180(18.0)$ & 0 & $180(36.1)$ & \\
\hline Student & $39(3.9)$ & $26(5.2)$ & $13(2.6)$ & \\
\hline Not employed & $30(3.0)$ & $20(4.0)$ & $10(2.0)$ & \\
\hline
\end{tabular}

Values are presented as number (\%). ${ }^{a}$ Chi-square test was used.

Cancer Center Institutional Review Board (NCC 2017-0137). All participants provided written informed consent for the survey.

\section{Results}

As a matter of course due to sampling methods, there was no significant difference in age distribution between men and women (Table 1).

The least and the most feared cancers in men were thyroid and lung cancer, respectively (Table 2). When men assumed the perspective of women, the least and the most feared cancers were thyroid and stomach cancer, respectively. Rank difference between 5-year relative survival rate and the least feared cancer showed that the most optimistic view was of stomach cancer, followed by cancer of bile duct and gallbladder in men. The least and the most feared cancers in women were thyroid and stomach cancer, respectively.
In terms of the least feared cancer, the men's guess was in line with the women's response for stomach cancer, lung cancer, thyroid cancer, pancreatic cancer, cancer of bile duct and gallbladder, breast cancer, and cervical cancer. In the case of ovarian cancer, liver cancer, and uterine cancer, men were less afraid of those cancers than women.

For the most feared cancer, the men's guess was in line with the women's response for stomach cancer, liver cancer, bladder cancer, cancer of bile duct and gallbladder, and leukemia. In the case of ovarian cancer, breast cancer, cervical cancer, and uterine cancer, men were more afraid of those cancers than women. The women's guess was in line with the men's response for colon cancer, lung cancer, renal cancer, cancer of bile duct and gallbladder, leukemia, and breast cancer.

When the fear rank scores for the least fearful cancer in men were compared between responses of men and guesses by women, men feared stomach cancer and thyroid cancer less than women's guesses (Table 3). When women assumed the perspective of men, women feared prostate cancer, renal 


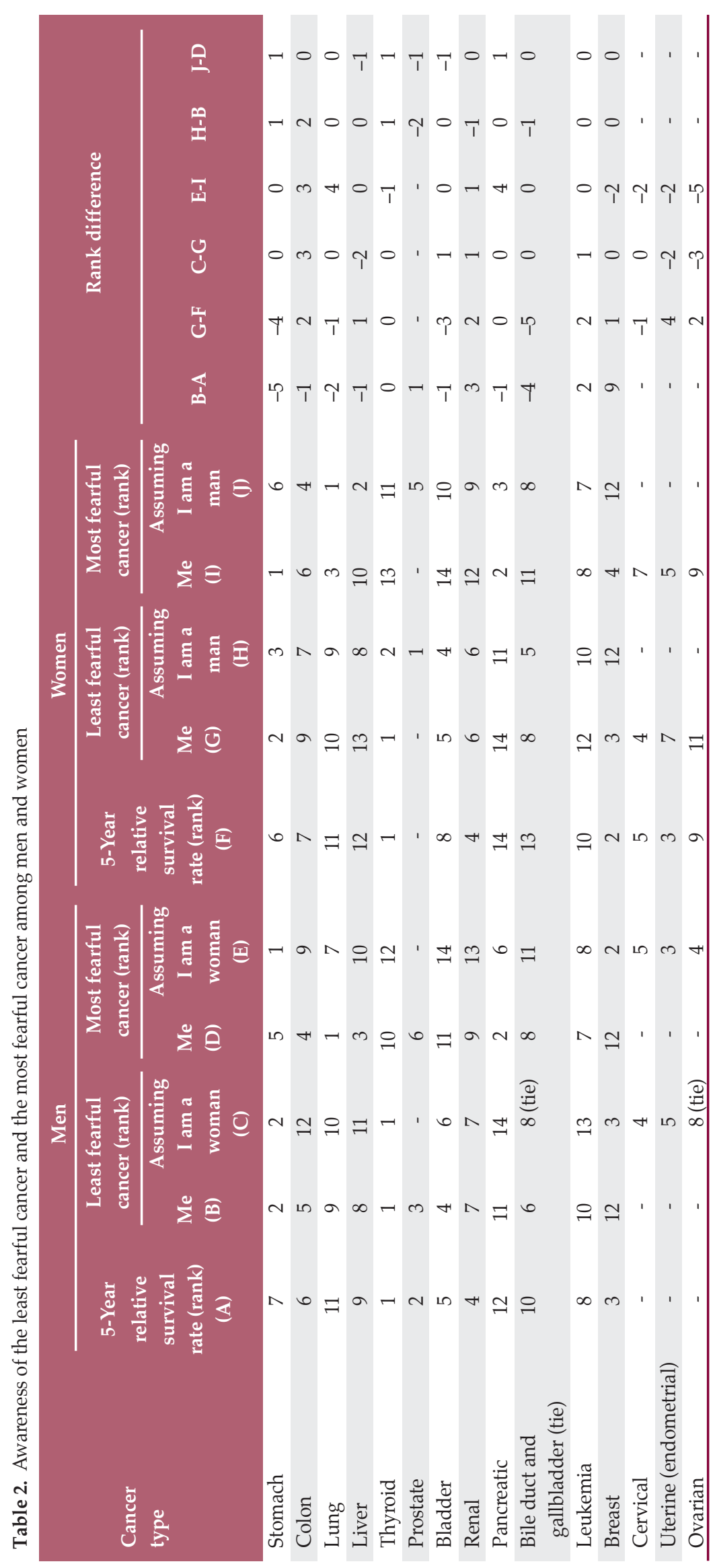




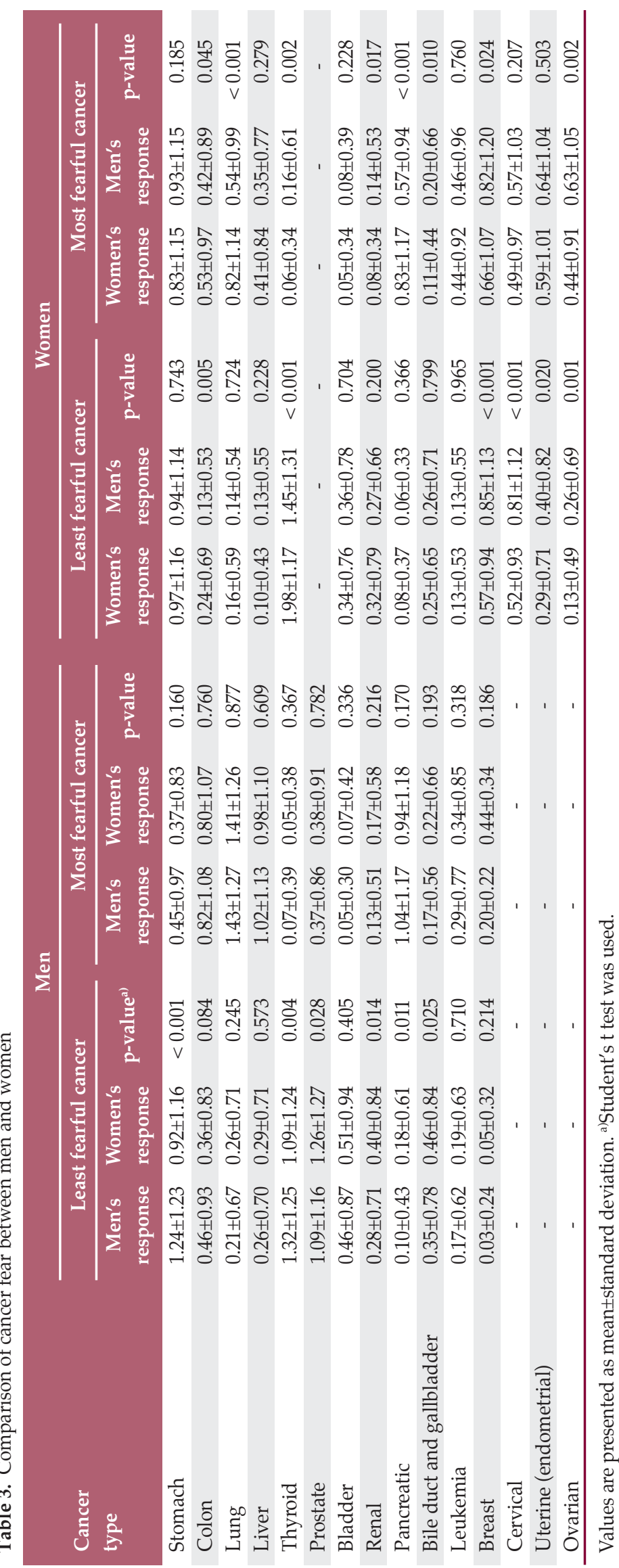


Table 4. Awareness of the most fearful side effects of cancer treatment among men and women

\begin{tabular}{lcccc} 
Side effect & $\begin{array}{c}\text { Total } \\
\text { (rank) }\end{array}$ & $\begin{array}{c}\text { Men } \\
\text { (rank) }\end{array}$ & $\begin{array}{c}\text { Women } \\
\text { (rank) }\end{array}$ & $\begin{array}{c}\text { Rank difference } \\
\text { (men-women) }\end{array}$ \\
Pain & 1 & 1 & 1 & 0 \\
Fatigue & 5 & 5 & 5 & 0 \\
General weakness & 3 & 3 & 3 & 0 \\
\hline Digestive dysfunction & 4 & 4 & 4 & 0 \\
\hline Sexual dysfunction & 9 & 8 & 2 & -3 \\
Psychological problems & 2 & 2 & 11 & 0 \\
Urological dysfunction & 10 & 9 & 9 & -1 \\
Motor dysfunction & 11 & 11 & 7 & 2 \\
\hline Sensory dysfunction & 7 & 10 & 6 & 3 \\
\hline Appearance change & 6 & 6 & 8 & 0 \\
\hline Lymphedema & 8 & 7 & 12 & -1 \\
Infertility & 12 & 12 & 0 \\
\hline
\end{tabular}

Table 5. Comparison of fear of side effects of cancer treatment between men and women

\begin{tabular}{lccc} 
Side effect & Men & Women & p-value \\
Pain & $2.07 \pm 1.20$ & $2.10 \pm 1.14$ & 0.703 \\
Fatigue & $0.49 \pm 0.90$ & $0.57 \pm 0.99$ & 0.169 \\
General weakness & $0.66 \pm 0.93$ & $0.82 \pm 1.01$ & 0.011 \\
Digestive dysfunction & $0.58 \pm 0.91$ & $0.65 \pm 0.95$ & 0.259 \\
Sexual dysfunction & $0.23 \pm 0.64$ & $0.08 \pm 0.40$ & $<0.001$ \\
Psychological problems & $0.83 \pm 1.08$ & $0.85 \pm 1.07$ & 0.776 \\
Urological dysfunction & $0.21 \pm 0.66$ & $0.09 \pm 0.39$ & 0.001 \\
Motor dysfunction & $0.10 \pm 0.44$ & $0.09 \pm 0.42$ & 0.780 \\
Sensory dysfunction & $0.16 \pm 0.53$ & $0.19 \pm 0.62$ & 0.500 \\
Appearance change & $0.41 \pm 0.82$ & $0.44 \pm 0.86$ & 0.525 \\
Lymphedema & $0.24 \pm 0.73$ & $0.11 \pm 0.45$ & 0.001 \\
Infertility & $0.01 \pm 0.16$ & $0.02 \pm 0.17$ & 0.842 \\
\hline
\end{tabular}

Values are presented as mean \pm standard deviation. ${ }^{\text {a) }}$ Student's $t$ test was used.

cancer, pancreatic cancer, and cancer of bile duct and gallbladder less than men. No statistically significant difference was found in case of the most feared cancer.

When the fear rank scores for the least fearful cancer in women were compared between responses of women and guesses by men, women feared colon cancer and thyroid cancer less than men's guesses. When men assumed the perspective of women, men feared breast cancer, cervical cancer, uterine cancer, and ovarian cancer less than women. In case of the most fearful cancer, women feared colon cancer, lung cancer, and pancreatic cancer more than men's guesses. When men assumed the perspective of women, men feared thyroid cancer, renal cancer, cancer of bile duct and gallbladder, breast cancer, and ovarian cancer more than women. Interestingly, in the case of breast and ovarian cancer, when asked about the least feared cancers, men rated those cancers less fearful than women, and men rated them more fearful than women when asked about the most feared cancer.
The most feared side effect of cancer treatment was pain, and the top six of the most feared side effects were identical for men and women (pain, psychological problems, general weakness, digestive dysfunction, fatigue, and appearance change) (Table 4). Sexual dysfunction, urinary disorders, and lymphedema were more feared side effects in men than in women. On the other hand, sensory dysfunction and motor dysfunction were more feared side effects in women than in men. When comparing fear rank scores for those side effects, general weakness was feared more in females, and sexual dysfunction, urological dysfunction, and lymphedema were feared more in males (Table 5).

\section{Discussion}

In this study, we found that there was an optimistic view of stomach cancer in both men and women. We believe this 
is because early detection of stomach cancer has been highly emphasized in Korea with the message that the rate of cure is very high if detected early [25]. With a gastric cancer screening rate of only $61.6 \%$ in 2018 [26], this optimistic view of stomach cancer may not help increase the screening rate. On the other hand, the reason for having a relatively optimistic fear perception for cancer of the bile duct and gallbladder is thought to be because the cancer is not well known for its subsistence despite the very poor survival rate. Cancer of the bile duct and gallbladder is not so prevalent, which ranks 9th in incidence respectively in males and females [27].

If both men and women assume that they are the opposite sex, the fear of sex-specific cancer was relatively lower compared to the actual responses of both men and women: prostate cancer in men, breast cancer, cervical cancer, uterine cancer, and ovarian cancer in women. This difference in thinking between men and women can affect mutual understanding in health problems related to cancer occurring in opposite sex, and also affect the behavior of health professionals [28].

Contrary to reports that most men fear prostate cancer because of fear of losing their masculinity [29], this study did not show much fear of prostate cancer. As a reason for this, it is presumed that unlike the West, especially in the United States, where the incidence of prostate cancer is low, there is limited opportunity to observe the side effects associated with prostate cancer treatment, such as the loss of masculinity.

It is interesting that the top six of the most feared side effects of cancer treatment were identical for men and women (pain, psychological problems, general weakness, digestive dysfunction, fatigue, and appearance change). In one study using a convenience sample of patients recently diagnosed with cancer, the rankings of the most feared side effects of cancer were different in men and women [30]. For women, it was hair loss, vomiting, infection, nausea, weight loss, shortness of breath (co-5th place), and fatigue. On the other hand, for men it was vomiting, infection, fatigue, weight loss, hair loss, and shortness of breath (co-5th place), followed by nausea. Because the respondents of this study consisted of people who had no experience of cancer for themselves or their family members, it is understandable that the responses of this survey may differ from the patients and their families. The fact that men fear more about urological and sexual dysfunction seems to have been rarely investigated in other studies, and further research is needed.

This study has the following strengths. Although it is not a large sample, it is a study conducted by a national survey by random probability allocation. In addition, by excluding cancer patients or families of cancer patients from the survey, experience-based responses could be eliminated as much as possible. It was difficult to find previous studies in which men and women responded assuming the perspective of the opposite sex as well as their own sex. This design allowed us to examine the idea of the opposite sex. However, the study has the following limitations. First of all, 1,460 respondents were contacted to enroll 1,000 respondents for this study, and the survey participation rate was $68.5 \%$. Although this participation rate is not low, the probability that some bias was involved in the representativeness of this sample cannot be excluded. In this study, when investigating the fear of cancer and side effects, a ranking score method was used to add up to the third place rather than just the frequency corresponding to the first place. In this case, even though statistical analysis can be diversified, and there are advantages to more inclusive analysis of the items answered in the top-level rankings, the differentiation between ranks may be weakened. With various judgments among respondents, more than 10 choices seem to have contributed to a widening of response variance. However, because cancer can be viewed as a collection of diseases rather than a single disease, expansion of options was inevitable. If more diverse questionnaires are constructed and qualitative studies are added to these variations, a more precise survey could be available.

Finally, since this study was conducted as a descriptive profiling study which summarized the differences in fear profiles between men and women, multivariate analysis was not used. Few studies have analyzed the fear of cancer types and side effects by sex to provide such cancer fear profile to health professionals. In this situation, we found it meaningful to present the results of this study to meet these needs. However, it can be said that there are limitations as a study for examining sex-specific effects by excluding the effects of other variables. Despite these limitations, while there are few studies comparing fears of cancer and side effects of cancer treatment between men and women, there are very few studies comparing those fears between men and women on the assumption of opposite sex, and this study has contributed to the accumulation of research literature.

In addition to the characteristics of the health problems caused by various types of cancer and the side effects of various types of cancer treatment, health care providers should provide care in response to the differences in these problems between men and women. Doctors can adequately and directly deal with the patient's emotional distress by verbally expressing understanding, empathy, support, and justification of emotion, which in turn leads to improvement in physical symptoms and the negative effects of insufficient social support [31]. The problem of communication in the medical field due to the difference in sex between health professionals such as doctors and patients due to changes in the sex ratio of medical service providers may also be an important issue in the future [32]. In order to prepare for this, it is necessary to educate the sex difference in the curriculum of health care professionals such as medical schools and nursing colleges. This will require understanding not only the biological aspects of sex, but also psychological and sociological aspects 
as well as training in communication skills.

In addition, family care givers, including spouses, will be able to provide more patient-friendly care if they communicate with each other, paying attention to the fact that there is a difference in the thought processes about cancer between men and women.

The least and the most feared cancers in men were thyroid and lung cancer, respectively. When men assumed the perspective of women, the least and the most feared cancers were thyroid and stomach cancer, respectively. The least and the most feared cancers in women were thyroid and stomach cancer, respectively. When women assumed the perspective of men, the least and the most feared cancers were prostate cancer and lung cancer, respectively. If both men and women assume that they are the opposite sex, the fear of sex-specific cancer was relatively lower compared to the actual responses of both men and women: prostate cancer in men, breast cancer, cervical cancer, uterine cancer and ovar- ian cancer in women. The most feared side effect of cancer treatment was pain, and the top six of the most feared side effects were identical for men and women (pain, psychological problems, general weakness, digestive dysfunction, fatigue, and appearance change). The fact that men fear more about urological and sexual dysfunction seems to have been rarely investigated in other studies, and further research is needed. Our findings highlight the importance of understanding the differences between men and women's attitudes and risk perception towards cancer.

\section{Electronic Supplementary Material}

Supplementary materials are available at Cancer Research and Treatment website (https://www.e-crt.org).

\section{Conflicts of Interest}

Conflicts of interest relevant to this article was not reported.

\section{References}

1. Mobbs D, Hagan CC, Dalgleish T, Silston B, Prevost C. The ecology of human fear: survival optimization and the nervous system. Front Neurosci. 2015;9:55.

2. Ropeik D. The consequences of fear. EMBO Rep. 2004;5(Suppl 1):S56-60

3. Aral SO, Douglas JM, Lipshutz JA. Behavioral interventions for prevention and control of sexually transmitted diseases. Boston, MA: Springer; 2007.

4. Rogers RW. Cognitive and psychological processes in fear appeals and attitude change: a revised theory of protection motivation. In: Cacioppo JT, Petty RE, editors. Social psychophysiology: a sourcebook. New York: The Guilford Press; 1983. p. 153-76.

5. Consedine NS, Magai C, Krivoshekova YS, Ryzewicz L, Neugut AI. Fear, anxiety, worry, and breast cancer screening behavior: a critical review. Cancer Epidemiol Biomarkers Prev. 2004;13:501-10.

6. Ferrer R, Klein WM. Risk perceptions and health behavior. Curr Opin Psychol. 2015;5:85-9.

7. Hong WK, Bas RC Jr, Hait WN, Kufe DW, Pollock RE. HollandFrei cancer medicine 8th ed. Shelton, CT: People's Medical Publishing House-USA; 2010.

8. Polanski J, Jankowska-Polanska B, Rosinczuk J, Chabowski M, Szymanska-Chabowska A. Quality of life of patients with lung cancer. Onco Targets Ther. 2016;9:1023-8.

9. Schulman-Green D, Ercolano E, Dowd M, Schwartz P, McCorkle R. Quality of life among women after surgery for ovarian cancer. Palliat Support Care. 2008;6:239-47.

10. Committee on Psychosocial Services to Cancer Patients/ Families in a Community Setting; Adler NE, Page AE. Cancer care for the whole patient: meeting psychosocial health needs. Washington, DC: National Academies Press; 2008.

11. Benz EJ Jr. The Jeremiah Metzger lecture cancer in the twenty- first century: an inside view from an outsider. Trans Am Clin Climatol Assoc. 2017;128:275-97.

12. Hernandez LM, Blazer DG, Committee on Assessing Interactions among Social, Behavioral, and Genetic Factors in Health. Genes, behavior, and the social environment: moving beyond the nature/nurture debate. Washington, DC: National Acade-mies Press; 2006.

13. Committee on Understanding the Biology of Sex and Gender Differences, Pardue ML, Wizemann TM. Exploring the biological contributions to human health: does sex matter? Washington, DC: National Academies Press; 2001.

14. Li QP, Mak YW, Loke AY. Spouses' experience of caregiving for cancer patients: a literature review. Int Nurs Rev. 2013;60: 178-87.

15. Ketcher D, Trettevik R, Vadaparampil ST, Heyman RE, Ellington L, Reblin M. Caring for a spouse with advanced cancer: similarities and differences for male and female caregivers. J Behav Med. 2020;43:817-28.

16. Hugman B. Perspectives on risk communication and gender issues. In: Harrison-Woolrych M, editor. Medicines for women. Cham: Adis; 2015. p. 531-83.

17. de Jonge ET, Vlasselaer J, Van de Putte G, Schobbens JC. The construct of breast cancer risk perception: need for a better risk communication? Facts Views Vis Obgyn. 2009;1:122-9.

18. Kim SE, Perez-Stable EJ, Wong S, Gregorich S, Sawaya GF, Walsh JM, et al. Association between cancer risk perception and screening behavior among diverse women. Arch Intern Med. 2008;168:728-34.

19. Vernon SW. Risk perception and risk communication for cancer screening behaviors: a review. J Natl Cancer Inst Monogr. 1999;1999:101-19.

20. Pellmar TC, Brandt EN Jr, Baird MA. Health and behavior: the interplay of biological, behavioral, and social influences: sum- 
mary of an Institute of Medicine report. Am J Health Promot. 2002;16:206-19.

21. Fawcett TN, McQueen A. Perspectives on cancer care. Chichester: Wiley-Blackwell; 2010.

22. Committee on the Learning Health Care System in America, Smith M, Saunders R, Stuckhardt L, McGinnis JM. Best care at lower cost: the path to continuously learning health care in America. Washington, DC: National Academies Press; 2013.

23. McQueen A, Vernon SW, Meissner HI, Rakowski W. Risk perceptions and worry about cancer: does gender make a difference? J Health Commun. 2008;13:56-79.

24. Shiloh S, Wade CH, Roberts JS, Alford SH, Biesecker BB. Associations between risk perceptions and worry about common diseases: a between- and within-subjects examination. Psychol Health. 2013;28:434-49.

25. Lee SY, Lee EE. Cancer screening in Koreans: a focus group approach. BMC Public Health. 2018;18:254.

26. National Health Insurance Service. 2018 National health screening statistics yearbook. Wonju: National Health Insur- ance Service; 2019.

27. Jung KW, Won YJ, Kong HJ, Lee ES. Prediction of cancer incidence and mortality in Korea, 2019. Cancer Res Treat. 2019;51: 431-7.

28. Celik H, Lagro-Janssen TA, Widdershoven GG, Abma TA. Bringing gender sensitivity into healthcare practice: a systematic review. Patient Educ Couns. 2011;84:143-9.

29. Kedrowski KM, Sarow MS. Cancer activism: gender, media, and public policy. Chicago, IL: University of Illinois Press; 2007.

30. Passik SD, Kirsh KL, Rosenfeld B, McDonald MV, Theobald $\mathrm{DE}$. The changeable nature of patients' fears regarding chemotherapy: implications for palliative care. J Pain Symptom Manage. 2001;21:113-20.

31. Epstein RM, Street RL Jr. Patient-centered communication in cancer care: promoting healing and reducing suffering. Bethesda, MD: National Institutes of Health; 2007.

32. van den Brink-Muinen A. The role of gender in healthcare communication. Patient Educ Couns. 2002;48:199-200. 